\title{
Development of the Frankfurt Youth Acculturation Scale (FRACC-Y)
}

Emily Frankenberg, Katharina Kupper, \& Stephan Bongard

Department of Psychology

J. W. Goethe-University Frankfurt am Main

Keywords: acculturation; migration; adolescents; scale

Corresponding author:

Prof. Dr. Stephan Bongard

Department of Psychology

Goethe-University Frankfurt

Theodor-W.-Adorno-Platz 6

D-60323 Frankfurt am Main

Germany

Phone: +4969 798-35321

Fax: $\quad+4969798-763-35321$

E-mail: bongard@psych.uni-frankfurt.de 


\begin{abstract}
This paper describes the development and psychometric properties of the Frankfurt Youth Acculturation Scale (FRACC-Y), a bidimensional instrument designed to assess orientation to culture of origin, orientation to host culture and acculturation strategy (i.e. assimilation, integration, separation and marginalization). Data were obtained from 292 adolescents in two German cities. Results of confirmatory factor analysis supported the postulated two-factor solution. The first 7-item factor measures orientation toward host culture, the second 5-item factor assesses orientation toward culture of origin. Both subscales yielded adequate internal reliability. Evidence for concurrent and discriminant validity is provided and implications for future research of acculturation in adolescents are discussed.
\end{abstract}


Development and Validation of the Frankfurt Youth Acculturation Scale (FRACC-Y) Recently, Germany has been subject to considerable demographic changes. The number of foreign citizens has nearly doubled within the past 30 years, reaching 7.2 million or $9 \%$ of the total population in 2010 (BAMF, 2010). The number of persons with migrational backgrounds, that is all immigrants and their descendants, is up to four times as large. With this increased diversification comes an increase in opportunities for intercultural encounters and thus a need for acculturation research. Acculturation research focuses on the changes in cultural attitudes and behaviors, which occur when two or more cultural groups and their individual members come into continuous contact with one another (Redfield, Linton \& Herskovits, 1936; Sam, \& Berry, 2006). The topic of this study is the measurement of psychological acculturation, that is the changes taking place on an individual level (Graves, 1967; see also Berry, 2005; Sam, 2006), which can concern behavior (e.g. language, clothing, social contacts, customs), attitudes, beliefs and cultural identity (Berry, 2005).

John W. Berry's (1997) bidimensional model of acculturation views migrants' maintenance of their cultural heritage and their adoption of mainstream culture as two separate, orthogonal dimensions (for a discussion on uni- vs. bidimensional models of acculturation see Berry, 2005; Ryder, Alden \& Paulhus, 2000). These two dimensions can be combined to define four acculturation strategies. Following the terminology set forth by Berry (e.g., 1980, 1997), these are: assimilation (pursuit of involvement with host culture while relinquishing one's culture of origin), integration (integrating elements of host and heritage culture), separation (preference for maintaining one's culture of origin without participating in the new culture) and marginalization (neither maintenance of heritage nor interaction with host culture).

Acculturation, therefore, is a complex, multidimensional process that can be even more so for adolescents, who face the threefold challenge of developmental changes, cultural 
adaptation and, oftentimes, socioeconomic advancement (Lynch, 1992; Phinney \& Landin, 1998). Research from more traditional immigration countries such as Australia, Canada or the USA suggests that immigrant children and adolescents are faced with multitudinous potential burdens due, for example, to differential profiles of acculturation within families and resulting conflicts (Portes \& Rumbaut, 2001). However, as has often been emphasized (e.g. Berry, 2005), findings from one societal context cannot be readily generalized to another. In order to gain an understanding of the unique challenges young immigrants face in Germany, their acculturation experiences need to be made available to research, necessitating the development of appropriate research instruments. The aforementioned societies with a longer tradition of immigration are further along in this process. In North America in particular, multiple measures of acculturation have been developed. Many of them are designed for use in specific ethnic groups only (e.g. ARSMA-II, Cuéllar, Harris \& Jasso, 1980; SL-ASIA, Suinn, Richard-Figueroa, Lew \& Vigil, 1987). Only few generic measures of acculturation exist that allow for administration to any ethnic group (e.g. Ryder et al., 2000; Stephenson, 2000). The use of group-specific instruments is supported by valid arguments (e.g. Obasi \& Leong, 2010), but limits potential research questions to the groups for which measures of acculturation exist. Considering that countries such as Germany are becoming home to more and more ethnic groups, developing unique scales for each of these is impracticable and unrealistic. In the current study alone, migrants of over 50 countries were represented and thus would have necessitated nearly as many different scales. Proponents of generic measures maintain that some aspects of the acculturation process are culturally universal (Headland, Pike \& Harris, 1990). Further, generic measures are more flexible and allow for implementation in individual or mixed group settings (such as classrooms).

One recently developed bi-dimensional, German-language measure of cultural orientation is the Frankfurt Acculturation Scale (FRACC, Bongard, Kelava, Sabic, Aazami-Gilan \& Kim, 
2007), a bidimensional 20 -item scale assessing acculturation orientation in adults. The purpose of the present study was to adapt this scale for use with adolescents. The thereby created Frankfurt Youth Acculturation Scale (FRACC-Y) is the first generic Germanlanguage acculturation scale for adolescents. It contains two subscales, C-Host: Orientation toward Host Culture and C-Origin: Orientation to Culture of Origin, yielding a separate score for each dimension. Though the two dimensions are often purported as being orthogonal, results rarely support a perfect orthogonal relationship. Phinney, Berry, Vedder and Liebkind (2006) found positive correlations for settler societies, suggesting biculturalism, while orientation to both cultures appeared to be incompatible in societies with shorter immigration histories. Highest negative correlations (of up to $-.39, \mathrm{p}<.001$ ) were found for Germany. Thus, we expected to find a negative correlation between the two subscales. Nonetheless, the FRACC-Y is conceptualized to allow for the cross tabulation of the two dimensions to form acculturation strategies as follows: High scores on C-Host (i.e. scores above scale midpoint) combined with low scores on C-Origin (i.e. scores equal to or lower than scale midpoint): Assimilation; high scores on both subscales: Integration; low scores on C-Host combined with high scores on C-Origin: Separation; and low scores on both scales: Marginalization. In line with previous findings (Berry, 2006), we expected the integration-strategy to be the most highly represented in the present sample.

The FRACC-Y was examined with regard to factor structure, internal consistency and validity. In accordance with Berry's model of acculturation, we expected to find two factors in the new measure, one representing orientation to the host culture, the other representing orientation to culture of origin. Additionally, the FRACC-Y was analyzed with regard to its concurrent validity. We expected a positive relationship between C-Host and a German test of crystallized intelligence, i.e. "acquired knowledge, information, and concepts specific to a culture" (O’Donnell, 2009, p. 155), since a stronger involvement in German society provides 
more opportunity to gain knowledge of German culture. Since language competency and preference have been shown to be a strong predictor of cultural adaptation and ethnic identity (Kang, 2006; Phinney, Romero, Nava \& Huang, 2001), it was hypothesized that C-Host would be positively related to German-language proficiency (as measured by academic grade and participant self-report). C-Origin was expected to be related to proficiency in the language of the country of origin. Along the same lines, highest C-Host scores were expected for adolescents living in German-speaking households, while the highest C-Origin scores were expected for students from households in which a non-German language was spoken exclusively. Adolescents living in bilingual households were expected to score second highest on both scales.

An aspect of discriminant validity was assessed as follows. Orientation to German culture was expected to be only weakly correlated with proficiency in the language of the culture of origin, while a similarly weak association was expected for orientation to culture of origin and German language proficiency. Because C-Host and C-Origin were not expected to be uncorrelated, null-correlations were not expected between either dimension and proficiency in the respective language of the other culture.

As indicators of good criterion-related validity we proposed the following. Since previous research has shown orientation to host culture to increase with generational status (Cuéllar, Arnold, \& Maldonado, 1995; Phinney et al., 2006), higher C-Host scores were expected for children born in Germany than for those born in their country of origin. Acquiring a country's citizenship is a formal sign of belonging or cultural affiliation (Sahin, Frankenberg, Ullrich, Bongard, \& van Dick, 2012; Bommes, 2011) and thus can be expected to promote orientation to and identification with the society in question. Thus, higher C-Host scores were expected for adolescents who hold German citizenship compared to those of foreign citizenship.

Cultural distance was chosen as a final indicator of criterion-related validity of the 
FRACC-Y subscales. The construct of cultural distance refers to the cultural differences existing between societies (Berry, 2006) and can be described in terms of several different dimensions, such as wealth, language, religion (Berry, 2006), individualism-collectivism and power distances (Hofstede \& Hofstede, 2006; see also Ringeisen, Schwarzer, \& Buchwald, 2008). Research has shown greater cultural distance to be an impediment to successful acculturation (Ward, Bochner, \& Furnham, 2001), since it requires greater culture shedding and can be associated with intercultural conflict (Berry, 2006). Thus, higher C-Host scores were expected for adolescents from countries with smaller cultural distance. The dimension chosen as a proxy for cultural distance was religious affiliation, since religious differences is one of two dimensions along which many psychological group characteristics have been shown to vary (Georgas, van de Vijver \& Berry, 2004; Steffen \& Merrill, 2011; for a review see Masgoret \& Ward, 2006). The religious orientations represented in this study were divided into four categories following those proposed by Phinney et al. (2006): no religion, Judeo-Christian, Muslim and Eastern religions (Buddhist and Hindu). Lower scores on CHost and higher scores on C-Origin were expected for students whose religions differed from Germany's predominantly Judeo-Christian belief system.

To assess an aspect of criterion-related validity of the acculturation strategies defined by the FRACC-Y, the Beck Depression Inventory (BDI-II) as a measure of psychological wellbeing. Research has repeatedly shown integration to be associated with the best psychological outcomes (e.g. Berry, 1997, 2006; Berry \& Sam, 1997). This has been ascribed to the fact that this strategy is associated with two sources of social support (see also Berry, \& Sabatier, 2011). Accordingly, we expected to find the lowest rates of depressive symptoms and best rating of classroom conduct for the integration group. Migration-related psychological problems have also been shown to follow a non-linear time courses, with a sharp increase upon initial contact (Berry, 2005). We expected this to result in a more diffuse pattern of 
psychological well-being among youth born in their countries of heritage. Thus, analyses were conducted separately for first- and second-generation migrants.

\section{Method}

\section{Participants and Procedure}

The total sample contained 292 students attending secondary schools in Frankfurt and Offenbach, Germany. Participants ranged in age from 10-20 years $(M=16.2, S D=2.75)$, $52.4 \%(n=153)$ were female, $45.9 \%(n=134)$ were male, with $1.7 \%(n=5)$ not reported. Over 50 countries of origin were represented, with the largest group being from Turkey $(n=$ 68), reflecting the national proportion of Turkish immigrants as the biggest group of immigrants living in Germany (BAMF, 2010). Of the total sample, 232 participants were second-generation migrants born in Germany, 59 were foreign-born and one participant did not indicate his or her place of birth.

Prior to data collection, participants (or a parent or guardian in the case of underage participants) gave informed consent. Confidentiality and anonymity of data were assured. Administration took place in classroom settings of 15 to 30 students per group.

\section{Materials}

Frankfurt Youth Acculturation Scale (FRACC-Y). An initial item pool was generated using those items of the FRACC (Bongard et al., 2007) pertaining to the life context of adolescents and adding further items derived from the acculturation literature. This initial version was pilot tested and subjected to a first revision process, during which all items that lowered the scales' reliability or showed unsatisfactory item difficulty and discrimination, i.e. discrimination below .4 (Moosbrugger \& Kelava, 2007), were removed. A 12-item scale emerged that consisted of positively worded items assessing behaviors and attitudes along two dimensions (C-Host: Orientation to Host Culture, $n=5$; C-Origin: Orientation to culture 
of origin, $n=7$ ). The represented domains include social affiliation, media usage and music preference, i.e. "I enjoy watching German television" (C-Host), or "I enjoy traveling to my country of origin," (C-Origin). Participants responded to the FRACC-Y using a 5-point Likert scale ranging from 0 (not at all true) to 4 (completely true). The items of the two scales were presented in mixed order as one questionnaire.

Wechsler Intelligence Scale for Children (WISC IV). The WISC IV, an intelligence test for children between the ages of 6 and 16, includes a Verbal Comprehension index (VCI), a composite score measuring verbal concept information. There is broad consensus that all of the VCI's subtests and supplementary subtests assess crystallized intelligence or culturally transmitted knowledge (O’Donnell, 2009; Prifitera, 2005), i.e. “the breadth and depth of a person's acquired knowledge of a culture and the effective application of this knowledge" (McGrew, \& Flanagan, 1998, p. 20). In the present study, a subtest of the German language version of the WISC IV (Petermann, \& Petermann, 2007) was applied. Due to time constraints and group setting, only the Word Reasoning-subtest was administered, yielding a good reliability $(\alpha=.85)$. This subtest generally shows high correlations with the $\operatorname{VCI}(r=$ 71) and total test score $(r=.67)$.

Academic grades. Academic grades received on the most recent report card for academic achievement in German class were obtained. The nature of academic grades, which represent a social comparison and are thus of limited comparability, necessitates a z-standardization of grade scores by class. In the present study, however, class-wise standardizations were not possible due to partially small numbers of children participating from each class. Instead, grades were standardized by school.

Beck Depression Inventory-II (BDI-II). The German version of the BDI-II (Hautzinger, Keller \& Kühner, 2006) is a 21-item measure of symptoms of depression using a 4-point Likert scale, ranging from 0 to 3, with high total scores indicating high rates of depressive 
symptoms. Internal consistency commonly ranges from .89 to .93 (Herzberg \& Goldschmidt, 2008) and was equally high in the present study $(\alpha=.90)$.

Demographic variables. Participants also responded to a questionnaire assessing demographic data. It included self-rating scales of German and native language abilities. Language proficiency was rated by participants on a 5-point Likert scale, ranging from 1 (none) to 5 (very good). It should be noted that none of the participants rated their knowledge of the German language as being worse than "sufficient" (=3), while for native language proficiency, all 5 levels were represented. Thus, the self-report scale of German language proficiency discriminated between 3 levels of German language proficiency: very good, good and sufficient,

\section{Results}

Below, the results of analyses examining the factorial structure, reliability and validity of the two FRACC-Y subscales as well as its employment as a measure of acculturation strategy are presented. Gender differences were not the subject of these analyses and will be presented elsewhere.

\section{Factorial Structure}

First, confirmatory factor analyses (CFA) were conducted in order to test whether the FRACC-Y would yield the postulated bidimensional factor structure in accordance with Berry's model of acculturation. The CFA model was estimated using Mplus (Muthen \& Muthen, 2010). As goodness-of-fit indices, $\chi^{2}$ test of model fit, standardized root mean squared residual (SRMR; Bentler, 1995), root mean squared error of approximation (RMSEA; Steiger \& Lind, 1980) and Comparative Fit Index (CFI; Bentler, 1990) were computed to evaluate the hypothesized two-factor model. This choice of indices follows the recommendations set forth by Byrne (1994) and $\mathrm{Hu}$ and Benter (1999). The $\chi^{2}$ test of model fit indicated a relatively poor fit $\left(\chi^{2}(53)=100.75, p<.001\right)$. This may, however, be 
accounted for by the small sample size, as this fit index is particularly size-sensitive (Fan, Thompson \& Wang, 1999) and those indices less dependent on sample size demonstrated a good fit. Hu and Bentler (1999) recommend a combinational rule based on the following fit indices and cut-off criteria: RMSEA of .06 or lower and SRMR of .09 or lower. In the present study, RMSEA equaled .056 and SRMR was .048, meeting Hu and Bentler's fit-evaluation criterion (1999; see also Browne \& Cudeck, 1992; Diamantopoulos \& Siguaw, 2000; Steiger, 2007). CFI $=.93$ also suggests an acceptable model fit (Byrne, 1994). The model with the standardized parameters is presented in Figure 1.

\section{Insert Figure 1 about here}

In order to assess the postulated low, negative relationship between the two subscales in accordance with findings by Phinney et al. (2006), a Pearson correlation was conducted. In concordance with expectations, the resulting correlation coefficient was found to be low but significant, accounting for $11 \%$ of the shared variance (see Table 1). As expected, the intercorrelation of the two factors was higher on the latent level (see Figure 1), since unreliability is partialed out in structural equation models. Thus, the two scales are not orthogonal, but can be viewed as factorially independent nonetheless, as evidenced by the low percentage of common variance and the CFA.

\section{Insert Table 1 about here}

Mean scores and standard deviations were $M=2.70, S D=0.69$ for C-Host and $M=2.67$, $S D=.91$ for C-Origin. Means and standard deviations for the 12 FRACC-Y items are presented in the Appendix.

\section{Reliability of the FRACC-Y}

In order to assess internal consistency, Cronbach's alpha coefficients were calculated. For C-Host, $\alpha$ was .70. C-Origin yielded an internal consistency of .74. Spearman-Brown splithalf coefficients were also calculated, yielding the following coefficients: C-Host: .74; C- 
Origin: .78. Thus, both FRACC-Y subscales showed adequate internal consistency and splithalf reliability.

\section{Validity of the FRACC-Y}

Framework according to Berry. Participants' scores were allocated to one of Berry's four acculturation strategies by means of scale mid-point split (with scores $>2.00$ defined as high and the scale's mid-point conservatively defined as low). In line with expectations based on previous research, integration proved to be by far the most represented attitude among both first- and second-generation migrants, at about two thirds (58.9\%) of all participants. Assimilation was the second most occurring strategy (24.7\%), followed by separation (14.0\%). Marginalization was hardly represented at all (2.4\%). Due to its weak representation $(n=7)$, marginalization was excluded from all further calculations.

\section{Criterion-oriented validity of the acculturation strategies.}

BDI-Scores. Data lent further support to the validity of the formation of acculturation strategies using the FRACC-Y scores. Since, after removal of the marginalization category, acculturation strategy represents a three-level categorical predictor, analysis of covariance (ANCOVA) was used to assess criterion-related validity while controlling for age. Due to the violation of the assumption of homogeneity of variance, a more stringent $\alpha$-level was used (.025), as suggested by Tabachnik and Fidell (2007). For students born in Germany, data yielded the expected difference at the $p=.002$ level in BDI-II scores between the four acculturation strategy groups: $F(3,220)=5.00, p=.002, \eta^{2}=.06$. As hypothesized, integration was associated with the lowest depression scores $(M=9.78, S D=8.01)$, followed by assimilation $(M=10.52, S D=8.78)$ and separation $(M=17.00, S D=14.09)$. For students born abroad, differences between acculturation strategy groups did not reach statistical significance.

\section{Criterion-oriented validity of the two subscales.}


Cultural knowledge and language proficiency. Both subscales displayed good concurrent and discriminant validity, as demonstrated by their pattern of partial correlations with knowledge of host culture and language ability (see Table 1). Prior to calculation, the validity of using the academic grade students received in German class as a supplemental proxy for German language proficiency was demonstrated by its significant correlation with selfreported German language proficiency $(R h o=.28, p<.001)$. After controlling for age and length of residency in Germany, C-Host was positively related to scores on the test of culturally transmitted knowledge (WISC IV). It was also positively related to academic German grade. ${ }^{1}$ In line with expectations, C-Origin was unrelated to either. The scales yielded similar correlation patterns for language proficiency. C-Host showed a positive relationship with German language proficiency as measured by participant self-report, while C-Origin showed a strong, positive relationship with self-reported proficiency of heritage language. CHost was expected to be weakly related or unrelated to proficiency in the language of the country of origin. Similarly, C-Origin was expected to be weakly related or unrelated to German language proficiency. In accordance with these expectations, C-Origin showed no significant relationship with German language proficiency. A low but significant negative relationship was found between C-Host and proficiency in language of the country of origin.

Generational status. As expected, children born abroad $(n=59)$ showed lower scores on C-Host $(M=2.54, S D=.72)$ than children born in Germany $(M=2.74, S D=.67), \mathrm{t}=2.07, p$ $=.04)$, though the effect size was small $\left(\eta^{2}=.01\right)^{2}$

Citizenship. One-way analyses of variance (ANOVA) were used to assess differences in cultural orientation between students with German, non-German or dual citizenship. In accordance with expectations, German citizens $(n=146)$ showed higher orientation to German culture $(M=2.81, S D=.69)$ than non-German citizens $(n=106 ; M=2.57, S D=$ $\left..69), F(2,282)=3.82, p=.02, \eta^{2}=.03\right)$. Students with German/non-German dual citizenship 
$(n=33)$ scored in between the other two groups $(M=2.61, S D=.61)$, but, as Tukey post-hoc tests revealed, did not differ significantly from either of them, $(p \geq .29)$. With regard to $\mathrm{C}$ Origin, the three groups' means followed the inverse pattern $\left(F(2,282)=6.95, p<.05 ; \eta^{2}=\right.$ .05). Post-hoc tests showed that German citizens displayed significantly lower C-Origin scores $(M=2.48, S D=.94)$ than German/non-German dual citizens $(M=2.85, S D=.83 ; p=$ $.02)$ and non-German citizens $(M=2.93, S D=.81 ; p=.004)$. The scores of the latter two groups did not differ significantly $(p=.88)$.

Household language. In accordance with expectations, students from German-speaking households scored highest in terms of C-Host $(n=40, M=3.20, S D=.54)$, students from bilingual households, in which one of the languages spoken was Germen, scored secondhighest $(n=134, M=2.68, S D=.65)$ and students from families that spoke no German at home lowest $(n=40, M=2.54, S D=.713 ; F(2,278)=14.64 ; p<.001)$. The effect size was moderate $\left(\eta^{2}=.09\right)$. The opposite was expected with regard to C-Origin. Conform to this hypothesis, students from German-speaking households scored lowest $(M=2.05, S D=1.05)$, bilingual second lowest $(M=2.63, S D=.82)$ and students from non-German-speaking households highest on C-Origin $\left(M=2.96, S D=.81 ; F(2,278)=16.96, p<.001, \eta^{2}=.11\right)$. Tukey post-hoc tests revealed that the all pair wise comparisons for both scales were significant with $p<.001$ to $p<.05$ with the only exception that those who came form bilingual households and those from non-German-speaking households did not differ significantly on the C-Host scale $(p=.23)$.

Cultural distance. An ANOVA was calculated to compare groups of different cultural distance. Results supported the hypothesis that the C-Origin-scale would be able to differentiate between students with a Judeo-Christian belief system $(n=86)$, Eastern religion ( $n=14)$, Muslim $(n=153)$ and those of no religion $(n=11 ; n=28$ not reported $)$. Muslims had the highest orientation to their culture of origin $(M=2.84, S D=.80)$, Judeo-Christians 
second highest $(M=2.52, S D=.98)$, and students of Eastern religious orientation or no religion received the lowest scores $(M=2.33, S D=1.02 ; M=2.13, S D=.99)$. The overall effect across conditions was significant, $F(3,260)=4.90, p=.003$, and of small to moderate size $\left(\eta^{2}=.05\right)$, although post-hoc tests revealed that only the pair wise comparisons between Muslims and Judeo-Christians and Muslims and persons of no religious affiliation reached statistical significance $(p=.03$ and $p=.048)$.

\section{Discussion}

The present study yielded promising results regarding the psychometric properties and factorial structure of the FRACC-Y and its two subscales, identified as orientation toward the culture of origin (C-Origin) and orientation towards the host culture (C-Host). The subscales showed adequate internal consistency in a diverse sample of young migrants. The distribution of acculturation strategies, as well as criteria covering residency, citizenship, family structure, household languages and cultural distance support the validity of the subscales. A generic format was chosen for the FRACC-Y in order to make it appropriate for use across ethnic groups, thus taking into account the ethnic and cultural plurality researchers face in Germany today. The scale's brevity allows for its inclusion in larger studies or community surveys and hence makes it practicable for use in research.

Confirmatory factor analysis supported the postulated two-factor model of acculturation as measured by the FRACC-Y. Data revealed the expected low but significant negative relationship between orientation to host culture and to culture of origin, while the small amount of shared variance confirmed the assumption of relative independence of the two subscales. The significant relationship between orientation to host culture and orientation to culture of origin is likely a reflection of the general attitude towards immigrants in Germany. Although public policy officially endorses integration, research has repeatedly shown the overall sentiment of the general public to expect migrants to assimilate (e.g. Zick, Wagner, 
van Dick, \& Petzel, 2001). Data lent further support the viability of both subscales to form the acculturation strategies according to Berry's two-dimensional acculturation model (Berry, 1996). In line with past research, integration was found to be the most popular acculturation strategy and was associated with more positive psychological adaptation, although this was only the case for students born in Germany. No significant acculturation group differences were found among foreign-born students, suggesting a non-linear pattern of psychological problems among newly immigrated migrants.

Strong criterion-oriented validity of the C-Host subscale was demonstrated by the scale's positive correlation with German language proficiency, as measured by participant self-report and academic grade, and cultural knowledge as well as its ability to differentiate between generational statuses, as measured by place of birth. As expected, migrants who were born in Germany showed stronger orientation to host culture. Similarly, C-Origin showed good concurrent validity in terms of its high, positive correlation with proficiency in the language of heritage. Further indicators of good criterion-related validity were citizenship, household language and cultural distance, with higher C-Host and lower C-Origin scores found for German citizens, students from German-speaking households and students sharing the German majority's religious orientation.

For C-Origin, a null-correlation with German language proficiency supported the subscale's discriminant validity. C-Host, however, was significantly negatively related to proficiency in the language of the country of heritage, indicating a loss of native language with increased adaptation to German culture. Though this is in line with the negative relationship found between orientation to host culture and culture of origin (Phinney et al., 2006), it is surprising that the absolute value of the correlation between orientation to German culture and native language proficiency was even higher than that of orientation to German culture and German language proficiency. The relationship between the FRACC-Y subscales 
and language proficiency should thus be the focus of future studies.

In sum, the FRACC-Y was found to be a valid and practicable tool for the assessment of acculturation orientation and acculturation strategies in adolescent migrants living in urban areas within Germany. The scale covers a broad spectrum of relevant domains such as language and media use, feeling of acceptance and social affiliation. In its present version, the C-Host subscale contains 7 items, while C-Origin is 5 items long. Future studies should aim at optimizing C-Host so that it, too, can be shortened to only 5 items without reducing its reliability.

It is important to note that the FRACC-Y assesses both acculturation attitudes and behaviors, conceptualizing acculturation as a psychological construct, which influences both behavior and attitudes. Though studies support this conceptualization (see Eagly \& Chaiken, 1993, for an overview), it has also been recommended that attitudes and behaviors be measured with separate scales (Arends-Tóth, van de Vijver \& Poortinga, 2006), making the combined measurement of attitudes and behaviors a potential limitation of the present study that must be reassessed in future research. In fact, the large variation in standard deviations observed on the individual item level might be the result of the heterogeneity of domains and item content. Four items displayed particularly high standard deviations above 1.3 - those pertaining to use, enjoyment or preference of music, television and businesses from the country of origin. One possible explanation for the high variability among the students' answers to these items is the (lacking) availability of television, music and shops or restaurants from the respective country in Germany. This might result in extreme answers, especially on the lower end of the scale, since all adolescents from countries, which are not represented in Germany in the form of small businesses or television channels, will mark the lowest answer option.

Data collection was based on non-random samples and was limited to two German cities, 
potentially limiting the generalizability of the findings. Further studies need to be conducted in order to assess whether the instrument is similarly applicable to other German-speaking countries or regions. Other aspects worth exploring is how the scale results might differ among migrants of various countries of origin.

The FRACC-Y is the first German-language measure of acculturation particularly designed for administration in adolescents. Its development was motivated by the increased need for a means of gaining insight into the acculturation process of adolescents in Germany. Once acculturation has been made available to research, so will the success of Germany's integration policy, which aims at promoting the social inclusion of all persons living in Germany. Cultural orientation, as measured with scales such as the FRACC-Y, is one aspect of this inclusion.

\section{Acknowledgments}

The authors gratefully acknowledge the support of Dipl. Psych. Tanja Könen with data analysis. 


\section{References}

Arends-Tóth, J., van de Vijver, F., \& Poortinga, Y.H. (2006). The influence of method factors on the relation between attitudes and self-reported behaviors in the assessment of acculturation. European Journal of Psychological Assessment, 22, 4-12.

BAMF. Brochure "Das Bundesamt in Zahlen 2010.” Retrieved from http://www.bamf.de/SharedDocs/Anlagen/DE/Publikationen/Broschueren/bundesamt-inzahlen-2010.html?nn=1367528

Bentler, P. M. (1990). Comparative fit indexes in structural models. Psychological Bulletin, 107(2), 238-246.

Bentler, P. M. (1995). ESQ structural equations program manual. Encino, CA: Multivariate Software.

Berry, J. W. (1980). Acculturation as varieties of adaptation. In A. Padilla (Ed.), Acculturation. Theory, Models and Some New Findings (pp. 9-25). Boulder: Westview.

Berry, J. W. (1997). Immigration, acculturation, and adaptation. Applied Psychology: An International Review, 46, 5-34.

Berry, J. W. (2005). Acculturation: Living successfully in two cultures. International Journal of Intercultural Relations, 29, 697-712.

Berry, J. W. (2006). Contexts of acculturation. In D. L. Sam \& J. W. Berry (Eds.). The Cambridge Handbook of Acculturation Psychology (pp. 142-160), Cambridge, UK: Cambridge University Press.

Berry, J. W., Phinney, J. S., Sam, D. L., \& Vedder, P. (2006). Immigrant youth in cultural transition. Mahwah, NJ: Lawrence Erlbaum Associates.

Berry, J. W., \& Sabatier, C. (2011). Variations in the assessment of acculturation attitudes: their relationships with psychological wellbeing. International Journal of Intercultural Relations, 35, 685-669. 
Bommes, M. (2011). Migration und Migrationsforschung in der modernen Gesellschaft. Eine Aufsatzsammlung. [Migration and migration research in modern society.] In Vorstand des Instituts für Migrationsforschung und Interkulturelle Studien der Universität Osnabrück (Eds.), IMIS-Beiträge, 38, 191-224.

Bongard, S., Kelava, A., Sabic, M., Aazami-Gilan, D., \& Kim, Y.B. (2007). Akkulturation und gesundheitliche Beschwerden bei drei Migrantenstichproben in Deutschland. [Acculturation and health complaints in three migrant samples in Germany.] In H. Eschenbeck, U. Heim-Dreger, \& C. W. Kohlmann (Eds.). Beiträge zur Gesundheitspsychologie (p. 53). Schwäbisch Gmünd, Germany: Gmünder Hochschulreihe Band 29.

Browne, M. W., \& Cudeck, R. (1992). Alternative ways of assessing model fit. Sociological Methods and Research, 21, 230-258.

Byrne, B. M. (1994). Structural equation modeling with EQS and EQS/Windows. Thousand Oaks, CA: Sage Publications.

Cohen, J.W. (1988). Statistical power analysis for the behavioral sciences (2nd ed.). Hillsdale, NJ: Lawrence Erlbaum Associates.

Cuéllar, I., Arnold, B., \& Maldonado, R. (1995). Acculturation Rating Scale for Mexican Americans-II: A revision of the original ARSMA scale. Hispanic Journal of Behavioral Sciences, 17, 275-304.

Cuéllar, I., Harris, L. C., \& Jasso, R. (1980). An acculturation scale or Mexican American normal and clinical populations. Hispanic Journal of Behavioral Sciences, 2, 199-217.

Diamantopoulos, A., \& Siguaw, J. A. (2000). Introducing LISREL. London: Sage Publications.

Eagly, A.H., \& Chaiken, S. (1993). The psychology of attitudes. Fort Worth, TX: Harcourt Brace Jovanovich. 
Fan, X., Thompson, B., \& Wang, L. (1999). Effects of sample size, estimation methods, and model specification on structural equation modeling fit indexes. Structural Equation Modeling: A Multidisciplinary Journal, 6, 56-83.

Georgas, J., van de Vijver, F. \& Berry, J. W. (2004). The ecocultural framework, eco-social indices and psychological variables in cross-cultural research. Journal of Cross-Cultural Psychology, 35, 74-96.

Graves, T. (1967). Psychological acculturation in a tri-ethnic community. South-Western Journal of Anthropology, 23, 337-350.

Hautzinger, M., Keller, F., \& Kühner, C. (2006). Beck Depressions-Inventar (BDI-II). Revision. Frankfurt/Main: Harcourt Test Services. German revision of Beck, A. T., Steer, R. A., \& Brown, G. K. (1996). Beck Depression Inventory-II (BDI-II). San Antonio, TX: Harcourt Assessment Inc.

Headland, T. N., Pike, K.L., \& Harris, M. (1990). Emics and Etics: The Insider/Outsider Debate. Newbury Park, CA: Sage.

Herzberg, P. Y., \& Goldschmidt, S. (2008). Beck Depressions-Inventar (BDI-II). Revision. Report Psychologie 33(6), 301-302.

Hu, L., \& Bentler, P. M. (1999). Cutoff criteria for fit indexes in covariance structure analysis: conventional criteria versus new alternatives. Structural Equation Modeling: A Multidisciplinary Journal, 6, 1-55.

Kang, S.-M. (2006). Measurement of acculturation, scale formats, and language competence: Their Implications for Adjustment. Journal of Cross-Cultural Psychology, 37, 669-693.

Lynch, E. W. (1992). From culture shock to cultural learning. In E. W. Lynch \& M. J. Hanson (Eds.), Developing cross-cultural competence: A guide for working with young children and their families (pp. 19-34). Baltimore: Paul H. Brooke.

Masgoret, A.-M., \& Ward, C. (2006). The cultural learning approach to acculturation. In D. 
L. Sam \& J. W. Berry (Eds.), Cambridge handbook of acculturation psychology (pp. 5877). Cambridge, England: Cambridge University Press.

Muthén, B., \& Muthén, L. (2010). Mplus User’s Guide (6th Ed.). Los Angeles, CA: Muthén \& Muthén.

O’Donnell, L. (2009). The Wechsler Intelligence Scale for Children-Fourth Edition. In J. A. Naglieri \& S. Goldstein (Eds.), Practitioner's Guide to Assessing Intelligence and Achievement

Obasi, E. M., \& Leong, F. T. L. (2010). Construction and validation of the measurement of acculturation strategies for people of African descent (MASPAD). Cultural Diversity and Ethnic Minority Psychology, 16(4), 526-539.

Petermann, F., \& Petermann, U. (2007). Hamburg-Wechsler-Intelligenztest für Kinder IV (3 ${ }^{\text {rd }}$ ed.). Bern: Huber.

Phinney, J. S., Berry, J. W., Vedder, P., \& Liebkind, K. (2006). The acculturation experience: attitudes, identities, and behaviors of immigrant youth. In J. W. Berry, J. S. Phinney, D. L. Sam, \& P. Vedder (Eds.). Immigrant Youth in Cultural Transition. Mahwah, New Jersey: Lawrence Erlbaum Associates.

Phinney, J. S., \& Landin, J. (1998). Research paradigms for studying ethnic minority families within and across groups. In V. Mcloyd \& L. Steinberg (Eds.), Conceptual and methodological issues in the study of minority adolescents and their families (pp. 89-109). Hillsdale, NJ: Erlbaum.

Phinney, J. S., Romero, I., Nava, M., \& Huang, D. (2001). The role of language, parents and peers in ethnic identity among adolescents in immigrant families, Journal of Youth and Adolescence, 30, 135-153.

Portes, A., \& Rumbaut, R. G. (2001). The story of the immigrant second generation: Legacies. Los Angeles: University of California Press. 
Redfield, R., Linton, R., \& Herskovitz, M. (1936). Memorandum on the study of acculturation. American Anthropologist, 38, 149-152.

Ryder, A. G., Alden, L. E., \& Paulhus, D. L. (2000). Is acculturation unidimensional or bidimensional? A head-to-head comparison in the prediction of personality, self-identity, and adjustment. Journal of Personality and Social Psychology, 79, 49-65.

Sahin, B., Frankenberg, E., Ullrich, J., Bongard, S., \& van Dick, R. (2012). Host culture identification of Turkish immigrants in Germany and in the Netherlands. Manuscript in progress, Department of Psychology, Johann Wolfgang Goethe-University, Frankfurt, Germany.

Sam, D. L. (2006). Acculturation: conceptual background and core components. In D. L. Sam \& J. W. Berry (Eds.). The Cambridge Handbook of Acculturation Psychology (pp. 1126), Cambridge, UK: Cambridge University Press.

Sam, D. L., \& Berry, J. W. (2006). Introduction. In D. L. Sam \& J. W. Berry (Eds.). The Cambridge Handbook of Acculturation Psychology (pp. 1-7), Cambridge, UK: Cambridge University Press.

Sam, D. L., Vedder, P., Ward, C., \& Horenczyk, G. (2006). Psychological and sociocultural adaptation of immigrant youth. In J. W. Berry, J. S. Phinney, D. L. Sam, \& P. Vedder (Eds.). Immigrant Youth in Cultural Transition. Mahwah, New Jersey: Lawrence Erlbaum Associates.

Steffen, P., \& Merrill, R. (2011). The association between religion and acculturation in Utah Mexican immigrants. Mental Health, Religion \& Culture, 14(6), 561-573.

Steiger, J. H. (2007). Understanding the limitations of global fit assessment in structural equation modeling. Personality and Individual Differences, 42, 893-898.

Steiger, J. H., \& Lind, J.C. (1980). Statistically based tests for the number of common factors. Paper presented at the annual meeting of the Psychometric Society, Iowa City, IA. Cited 
in: Fan, X., Thompson, B., \& Wang, L. (1999). Effects of sample size, estimation methods, and model specification on structural equation modeling fit indexes. Structural Equation Modeling: A Multidisciplinary Journal, 6, 56-83.

Stephenson, M. (2000). Development and validation of the Stephenson Multigroup Acculturation Scale (SMAS). Psychological Assessment, 12, 77-88.

Suinn, R. M., Rickard-Figueroa, K., Lew, S., \& Vigil, P. (1987). The Suinn-Lew Asian Selfidentity Acculturation Scale: An initial report. Educational and Psychological Measurement, 47, 401-407.

Tabachnik, B.G., \& Fidell, L.S. (2007). Using multivariate statistics $\left(5^{\text {th }} \mathrm{rev}\right.$. International ed.). New Jersey: Pearson Education.

Ward, C., Bochner, S., \& Furnham, A. (2001). The psychology of culture shock. Hove: Rutledge.

Zick, A., Wagner, U., van Dick, R., \& Petzel, T. (2001). Acculturation and prejudice in Germany: Majority and minority perspectives. Journal of Social Issues, 57, 541-557.

\section{Footnotes}

${ }^{1}$ Academic grades were transformed from the usual German system so that higher grades designate better performance.

${ }^{2}$ Following Cohen's (1988) guidelines: small $\left(\eta^{2}=.01\right)$, medium $\left(\eta^{2}=.06\right)$ and $\left(\eta^{2}=\right.$ .14) large effect size. 


\section{Tables}

\section{Table 1}

Pearson and Spearman's Rho Correlation Coefficients between the FRAKK-Y Subscales and HAWIK, Language Proficiency, German academic grade, and BDI-II

\begin{tabular}{lccccccccc}
\hline & C-H & C-O & HAWIK & Host & Orig. & BDI-II & Grade & Work & Social \\
& & & & & & \\
& & & & & & \\
\hline $\mathrm{C}-\mathrm{H}$ & - & $-.26^{* * *}$ & $.19^{* *}$ & $-.17^{* *}$ & $.17^{* *}$ & $-.27^{* * *}$ & $.12^{*}$ & .03 & .01 \\
$\mathrm{C}-\mathrm{O}$ & - & - & .00 & -.05 & $.49^{* * *}$ & .02 & .04 & .05 & -.02 \\
\hline
\end{tabular}

Note. C-Host= Orientation to Host Culture; $\mathrm{C}$-Origin $=$ Orientation to Culture of Origin; HAWIK = Subtest of culturally transmitted knowledge; Host lang. = German language proficiency according to participant self-report; Orig. lang. = Proficiency in the language of origin; BDI-II = Beck Depression Inventory; Grade = Academic grade for the subject German; Work $=$ Teacher rating of classroom work behavior; Social $=$ Teacher rating of classroom social behavior.

$* p<.05 . \quad * * p<.01 . \quad * * * p<.001 \quad$ (2-tailed). 
Figures

Figure 1

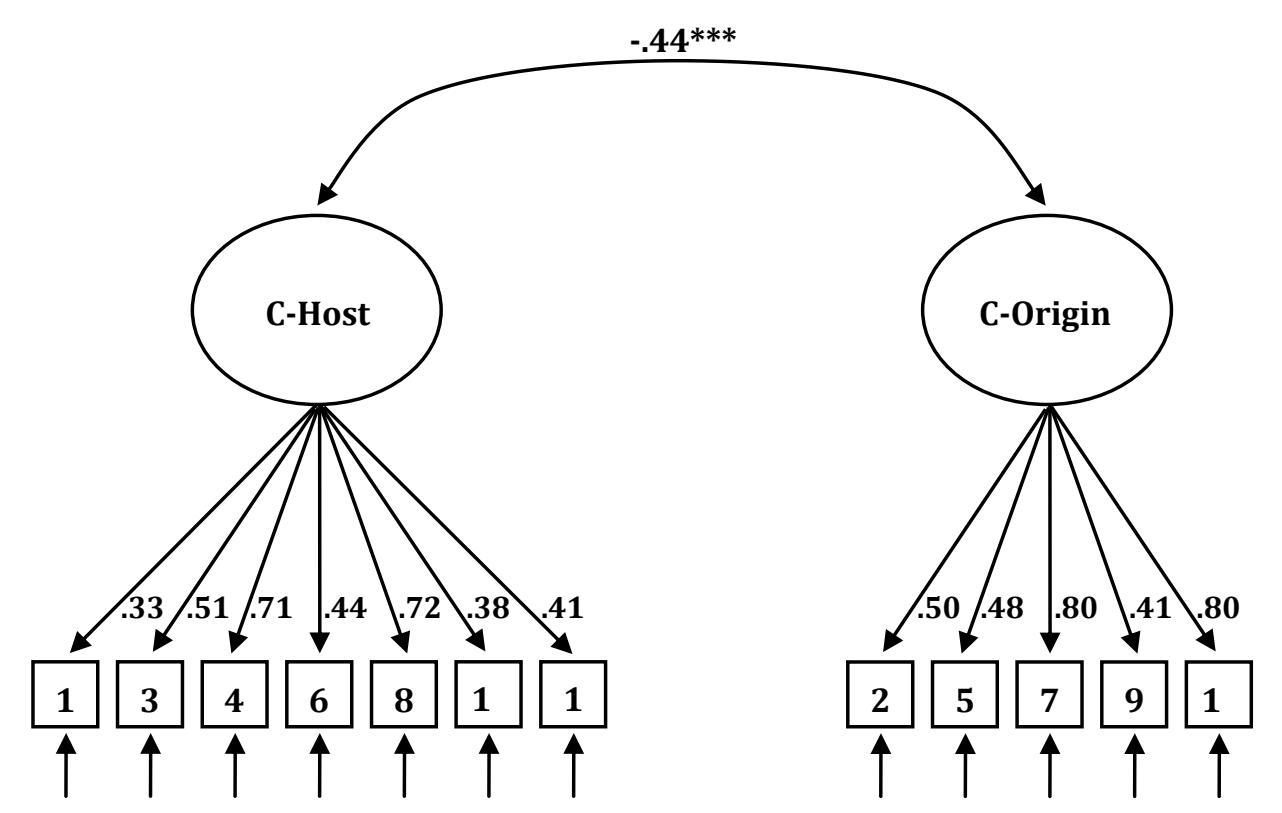


Appendix

Item Content, Means, and Standard Deviations for the FRACC-Y

FRACC-Y Items

Subscale 1: Orientation to Host Culture

1. Acceptance by German peers

$3.32 \quad .98$

3. Use of German television

$3.30 \quad .95$

4. Enjoyment of living in Germany

$3.00 \quad 1.08$

6. German social contact

$1.91 \quad 1.07$

10. Spending future in Germany

$2.91 \quad 1.23$

11. German songs

$2.74 \quad 1.29$

12. Support of German athletes

\section{Subscale 2: Orientation to Culture of Origin}

2. Enjoyment of travel to country of heritage

5. Frequenting small businesses from members of country of heritage

7. Use of television from country of origin

8. Music from country of origin

9. Speaking heritage language*

$3.68 \quad .85$

Note. All of the items used a 5-point Likert scale (0 strongly disagree - 4 strongly agree).

English items are not direct translations and have not been validated.

*) Item needs to be inverted before calculating the C-Origin-score. 